\title{
AN OVERVIEW OF SRI LANKAN SEA SNAKES WITH AN ANNOTATED CHECKLIST AND A FIELD KEY
}

\author{
Ruchira Somaweera ${ }^{1}$ and Nilusha Somaweera ${ }^{2}$
}

\footnotetext{
${ }^{1}$ Reptile Ecology Lab, School of Biological Sciences, The University of Sydney, Australia.

${ }^{2}$ University of Sydney Tropical Ecology Research Facility, Northern Territory, Australia.

${ }^{1}$ Corresponding author: ruchira.somaweera@gmail.com
}

\begin{abstract}
Sea snakes of Sri Lanka has not received much attention and the last few decades did not see any unprecedented increase in interest in these largely ignored (in Sri Lanka) snakes, despite heavy attention has been made on certain other groups of herpetofauna. Hence, a new checklist and an overview in 'general literature' are much needed. This contribution provides an enumeration of the recorded species, together with an overview of the natural history of the group and a set of field keys for species found in Sri Lankan waters.
\end{abstract}

Keywords: sea snakes, sea kraits, natural history, distribution, identification key, Sri Lanka

\section{Introduction}

Sea snakes: Snakes of at least five distinct lineages inhabit the marine environment. These comprise the file snakes (family Acrochordidae), the mud snakes (family Colubridae: subfamily Homalopsinae), the water snakes (family Colubridae: subfamily Natricinae), the sea kraits (family Laticaudidae) and the true sea snakes (family Hydrophiidae) (Heatwole, 1999), though the term 'sea snake' mainly refers to the sea kraits and the true sea snakes. Wall (1909) in the first monograph on sea snakes identified 11 genera and followed Boulenger (1986)'s classification where all sea snakes were placed under subfamily Hydrophiinae in family Elapidae. Subsequently Smith (1926) in his monograph on sea snakes grouped all sea snakes under family Hydrophiidae which he further divided into two subfamilies: Hydrophiinae and Laticaudinae with Laticauda as the most primitive genus in the latter. All subsequent authors including Dowling (1959 \& 1967), Underwood (1967 \& 